\title{
SIGNIFICANCE OF SEXUAL REPRODUCTION OF PHYTOPHTHORA INFESTANS IN THE CZECH REPUBLIC
}

\author{
Jana Mazáková1, Miloslav Zouhar ${ }^{1}$, Pavel Ryšánek ${ }^{1}$ \\ ${ }^{1}$ Department of Plant Protection, Faculty of Agrobiology, Food and Natural Resources, Czech University of Life \\ Sciences Prague, Kamýcká 129, 16500 Prague, Czech Republic
}

To cite this article: MAZÁKOVÁ JANA,ZOUHAR MILOSLAV, RYŠÁNEK PAVEL. 2018. Significance of Sexual Reproduction of Phytophthora Infestans in the Czech Republic. Acta Universitatis Agriculturae et Silviculturae Mendelianae Brunensis, 66(5): 1191-1197.

To link to this article: https://doi.org/10.11118/actaun201866051191

\begin{abstract}
A total of 187 naturally late blight-diseased potato leaves were sampled from 31 sites and five regions of the Czech Republic during the growing season in 2012-2014 and 2016 and examined microscopically for the ability of Phytophthora infestans to produce oospores in infected leaves under field conditions. Although the occurrence of the A1 and A2 mating types required for sexual reproduction of P. infestans was previously confirmed in the Czech Republic, no oospores were detected in this study. To study the effect of temperature on the survival of oospores produced from crosses of three pairs of P. infestans isolates, oospores in leaf discs and agar were exposed to temperatures ranging from -24 to $10{ }^{\circ} \mathrm{C}$ and then evaluated for viability with the plasmolysis test. Oospore viability ranged from 13.02 to $63.90 \%$ and from 7.77 to $63.37 \%$ for oospores produced in agar and leaf discs, respectively, with the highest frequencies of viable oospores occurring at 4 and $10^{\circ} \mathrm{C}$. To determine whether oospores may survive under field conditions, agar plates with oospores were buried in soil in Prague-Suchdol and Svitavy for seven months during the overwintering period (October-May) in 2011-2015. There were statistically significant differences in oospore viability examined by the plasmolysis test between the localities, and oospore viability ranged from 29 to $43 \%$ and from 15 to $44 \%$ in Prague-Suchdol and Svitavy, respectively.
\end{abstract}

Keywords: potato late blight, mating type, oospores, overwintering

\section{INTRODUCTION}

Potato late blight is well known for its notorious role in the Irish potato famine in the 1840s. Even today, despite the effective control of this disease using the combination of integrated late blight management strategies (cultural practices, resistant cultivars, fungicide treatment, and a decision support system), the causal agent of the disease, Phytophthora infestans (Mont.) de Bary, remains a devastating and re-emerging pathogen of potatoes and, thus, a major focus of researchers, potato breeders and fungicide producers. Furthermore, a survey recently performed by Kamoun et al. (2015) rated P. infestans first in the list of the top 10 oomycete pathogens in molecular pathology.

Because of the polycyclic nature of P. infestans, under favorable conditions, the asexual life cycle is completed and repeated multiple times during the host vegetative period, resulting in the production of a substantial number of asexual spores. Airborne sporangia release motile biflagellated zoospores or germinate directly and are responsible for the explosive course of the late blight epidemic (Fry, 2008). Although P. infestans primarily 
reproduces asexually, sexual reproduction occurs in the pathogen as it does in most oomycete species (Judelson, 2007). The heterothallic nature of P.infestans allows the production of oospores if the hyphae of opposite mating types, known as Al and A2, interact (Drenth et al., 1995). Until the 1980s, the global population of $P$. infestans was dominated by two clonal lineages, initially by HERB-1 in the nineteenth century (Yoshida et al., 2013), which was then replaced by a close relative, the US-1 genotype, in the twentieth century (Goodwin et al., 1994); both lineages were the Al mating type, which limited other populations to asexual reproduction (Fry et al., 2015). By contrast, the coexistence of both mating types was known to be present only in the central highlands of Mexico, one of the probable centers of origin and diversity of P. infestans (Niederhauser, 1991). Since the report of Hohl and Iselin (1984), the composition of the P. infestans population outside Mexico began to change. New genotypes including the A2 mating type were introduced into other potato-growing areas of the world via the importation of infected potatoes from Mexico to Europe in 1976 and subsequent international trade of potato seeds (Niederhauser, 1991). Through long-distance migration, new, fitter and more variable genotypes spread and caused significant changes and an increase in genetic variability in $P$. infestans populations, resulting in the resurgence of late blight worldwide (Fry and Goodwin, 1997a; Fry and Goodwin, 1997b; Fry et al., 2013). The major sources of genetic variability within asexual, clonal lineages of P. infestans are mutation, migration and mitotic recombination (Goodwin, 1997), while oospores constitute a potential source of genetic variation via meiotic recombination. Moreover, sexual reproduction also provides the pathogen with the possibility of surviving in the soil for up to several years (Turkensteen et al., 2000). Thus, in addition to pathogen mycelium that survives in infected tubers between seasons, oospores in soils are another source of primary inoculum for late blight epidemics in the following seasons.

Although the A2 mating type was for the first time observed in 2003 and has been subsequently found in the Czech Republic in other years (Mazáková et al., 2006; Mazáková et al., 2010; Sedlák et al., 2017), there is little information about the possibility of oospores being produced and overwintering under field conditions in this region (Mazáková et al., 2010). Therefore, the purposes of the present study were 1) to investigate whether oospores are formed in leaf tissue in the Czech Republic and 2) to test the viability of oospores under laboratory and controlled environmental conditions.

\section{MATERIALS AND METHODS}

\section{Detection of oospores in leaf tissues}

In total, 187 samples of naturally late blight-diseased potato leaves were collected from 31 sites in two major potato-growing regions of the Czech Republic (the Vysočina Region and the Central Bohemia Region) and in three other regions (the Pardubice Region, the Plzen Region and the Prague Region) during four growing seasons (2012-2014 and 2016). The majority of the samples originated from crops in commercial growers' fields and research station fields, and some were obtained from volunteer plants and gardens. Each potato leaf was transported in an individual plastic bag to the laboratory and immediately processed. A single leaflet with two or more lesions was placed with the abaxial side up into a glass Petri dish containing three layers of moistened filter paper and incubated at $16-18{ }^{\circ} \mathrm{C}$ in the dark for $2-3$ weeks. A total of 413 segments $(15 \times 15 \mathrm{~mm})$ were selected from the leaf lesions and excised by using sterile scissors. Up to three lesions per leaf were selected, yielding an average of 2.2 leaf segments per leaf. The leaf segments were clarified in boiling ethanol (96\%) for 10 min, mounted in glycerol on a microscope slide or directly mounted on a glass slide, gently squashed with a cover slip, and examined microscopically for the presence of oospores.

\section{Source of isolates}

Six isolates of P. infestans of opposite mating types, namely, H6/09, JC1/09 and L27/09 (A1 mating type) and $\mathrm{Ml} / 09$, V4/09 and Bel/09 (A2 mating type), originating from six different sampling sites were chosen from a large collection of isolates based on previous experiments (unpublished data) and used in this study. All isolates were maintained on rye A agar in the dark at $16-18^{\circ} \mathrm{C}$. To recover the viability and pathogenicity of the isolates, which are especially important for in vivo tests, long-term cultivated cultures of P. infestans isolates were inoculated on potato leaves. Sporangia were harvested by washing the surface of Petri dish cultures with sterile double-distilled water (SDW). Sporangial suspension adjusted to a concentration of $15 \times 10^{3}$ sporangia ml-1 was cooled at $4^{\circ} \mathrm{C}$ for approximately $2-3 \mathrm{~h}$ to release zoospores. Fully expanded leaflets from potato cv. Ditta that was grown in the greenhouse were placed with the abaxial side up in a moist chamber (a 10-mm Petri dish with moistened filter papers). Each leaflet was inoculated with a 50- $\mu \mathrm{l}$ inoculum droplet $\left(5 \times 10^{4}\right.$ sporangia and zoospores $\left.\mathrm{ml}^{-1}\right)$. After incubation at $15-16{ }^{\circ} \mathrm{C}$ with a $16 \mathrm{~h}$ light/8 h dark photoperiod for 7 days, the pathogen was re-isolated on agar (Mazáková et al., 2010).

\section{Oospore production in agar and leaf tissue}

All recovered isolates were used for oospore formation in vitro and in vivo in three different pairings (H6/09:Ml/09, JCl/09:V4/09 and L27/09:Be1/09). Mycelial plugs (9 mm) cut using a flame-sterilized cork borer from the margin of 2 -week-old actively growing colonies of isolates were placed $30 \mathrm{~mm}$ apart in a 90-mm Petri dish containing rye $\mathrm{B}$ agar. After 3 weeks of incubation at $16-18{ }^{\circ} \mathrm{C}$ in the dark, the presence of oospores 
at the hyphal interfaces was observed under a light inverted microscope.

To produce oospores in vivo, 15-mm-diameter discs were cut with a cork borer from fully expanded leaflets that were excised from greenhouse-grown potato cv. Ditta plants. The leaf discs were floated with the abaxial surface pointing up in a 24-well tissue culture test plate (Orange Scientific, Braine-l'Alleud, Belgium). Each well contained $1 \mathrm{ml}$ of SDW. P. infestans inoculum was prepared by washing sporangia from the surface of 2-week-old isolate cultures. The sporangial suspension was adjusted to a concentration of $15 \times 10^{3}$ sporangia $\mathrm{ml}^{-1}$ using a Bürker chamber and then cooled at $4{ }^{\circ} \mathrm{C}$ for approximately $2-3 \mathrm{~h}$ to induce zoospore release and to obtain a spore density of approximately $2.5-5 \times 10^{4}$ spores $\mathrm{ml}^{-1}$. Twenty microliter drops (10 $\mu \mathrm{l}$ of each mating type) of a suspension containing 500 to 1000 sporangia and zoospores were placed in the center of each disc. The plates were incubated at $15-16{ }^{\circ} \mathrm{C}$ with a $16 \mathrm{~h}$ light/8 $\mathrm{h}$ dark photoperiod for two weeks. Some of the leaf discs were selected for verifying the presence of oospores in leaf tissue according to the method described above. Leaf discs chosen for testing were dried on sterile filter paper, and each was transferred in an individual sterile glass vial capped with a filter screw cap.

\section{Oospore survival under laboratory conditions}

To simulate different temperatures under laboratory conditions, 3-week-old cultures with oospores in agar plates sealed with parafilm and 2-week-old leaf discs with oospores placed in individual sterile glass vials were placed in thermostats. Oospores were exposed to six different temperatures: one temperature $\left(10^{\circ} \mathrm{C}\right)$ close to the average annual temperature, two temperatures (4 and $0{ }^{\circ} \mathrm{C}$ ) delimiting average winter temperature and three extreme temperatures $\left(-4,-10\right.$ and $\left.-24^{\circ} \mathrm{C}\right)$. There were ten replicates for each pairing and for each temperature. Oospores were evaluated after sixty days for viability using the plasmolysis test.

\section{Oospore survival under field conditions}

To test the overwintering ability of oospores, rye agar plates sealed with several layers of parafilm were placed in a plastic box and buried at a depth of $10 \mathrm{~cm}$ in two localities (Prague-Suchdol, the Prague Region, and Svitavy, the Pardubice Region). Prague-Suchdol is a warmer and drier region, whereas Svitavy generally has a higher and longer-lasting snow cover. Oospores were buried at the end of October in years 2011-14, recovered at the end of May of the next year and then processed in the laboratory for a viability test. There were ten replicates for each pairing and for each locality and year.

\section{Oospore viability}

The hyphal interaction zones with oospores were excised from the agar using a sterile scalpel and transferred to sterile $50-\mathrm{ml}$ centrifuge tubes containing $10 \mathrm{ml}$ of SDW. The leaf discs were also placed in sterile 50-ml centrifuge tubes containing $5 \mathrm{ml}$ of SDW. Oospores were extracted by blending the mycelial plug or leaf disc in SDW using an IKA homogenizer (T 25 digital ULTRA-TURRAX ${ }^{\circledast}$ ) with a S $25 \mathrm{~N}-10 \mathrm{G}$ probe (20000 rpm for $1 \mathrm{~min}$ ). The oospore suspension was filtered through a sterilized nylon net filter with 50 and $20 \mu \mathrm{m}$ pore sizes (Millipore, Merck, Darmstadt, Germany). Oospores that were collected on the $20 \mu \mathrm{m}$ nylon net filter were resuspended in SDW. The oospore suspension was adjusted to a concentration of $1 \times 10^{4}$ oospores $\mathrm{ml}^{-1}$ using a Bürker chamber. Plasmolysis tests were performed to determine the viability of the P. infestans oospores. The oospore suspension was treated with an equivalent volume of $4 \mathrm{M} \mathrm{NaCl}_{2}$ for $3 \mathrm{~h}$ at $20^{\circ} \mathrm{C}$. In total, 100 oospores in three replicates per Petri dish and leaf disc were assessed microscopically for plasmolysis, and viability was expressed as the percentage of oospores that were plasmolyzed.

\section{Data analysis}

The statistical analyses of the obtained data were performed using Statistica version $12 \mathrm{CZ}$ for Windows. One-way analysis of variance with a post hoc Tukey's honest significance test was applied to examine the effect of different temperatures and winter periods on the viability of oospores under laboratory and field conditions, respectively.

\section{RESULTS AND DISCUSSION}

No oospores were found in potato leaflets with two or more lesions in any sampling sites in any years of the survey. In a previous study in which isolates of P. infestans were collected from the same late-blighted samples and assessed for mating types, Sedlák et al. (2017) reported the presence of both mating types at 13 out of 31 sampling sites. This finding indicates the potential for sexual reproduction; however, the ratio of both mating types was significantly different from $1: 1$ at nine sites; therefore, the formation of oospores could be limited. In the sampling site at Valečov, for samples taken from the same field in two different sampling periods in 2013, 2014 and 2016, later potato late blight infections also did not include mixed populations of P. infestans in the field, resulting in no oospore formation. An essential environmental factor affecting oospore formation in host tissues in the field is a sufficient and continuous water supply (Cohen et al., 1997, Cohen et al., 2000). The fact that the weather conditions throughout the years of the survey were unusual and unfavorable for the occurrence of $P$. infestans in field-grown potato plants suggests that the absence of oospores resulted from a lack of free moisture. Sexual reproduction in detached leaves is abundant when such leaves are floating on water (Cohen et al., 1997). Although in our study leaflets were incubated in a humid chamber to support the merging of lesions and the formation 
of oospores before examination, the availability of free moisture had no effect on oospore formation. This result suggests the merging of late-blight lesions originating from the same mating type of the pathogen occurred, although self-mating in P. infestans strains forming oospores is sometimes present in the population to a much smaller extent (Pipe et al., 2000). Oliva et al. (2002) mentioned that the coexistence of the Al and A2 mating types apparently does not always lead to sexual reproduction; thus, only clonal populations of P. infestans may be present. However, circumstantial evidence of possible sexual reproduction has been reported in Europe and North America (Drenth et al., 1994; Gavino et al., 2000; Knapova and Gisi, 2002; Sujkowski et al., 1994). In contrast, there is strong evidence of oospore formation in fields in European countries including Germany (Götz, 1991), Sweden (Andersson et al., 1998), the Netherlands (Turkensteen et al., 2000), and Nordic countries (Yuen and Andersson, 2013). In the Czech Republic, a survey during 2007 and 2008 showed the first occurrence of oospores of P. infestans in five leaves that originated from a field located in Lípa in the Vysočina region in 2008 (Mazáková et al., 2010).

Oospores are capable of surviving under adverse environmental conditions. The survival of oospores of P. infestans that have been exposed to various environmental conditions can be evaluated with a germination test, tetrazolium staining and the plasmolysis method as different measurements of oospore viability (Flier et al., 2001). However, the dormancy of oospores may prevent the germination of oospores and complicate germination assays, especially for the heterothallic species of Phytophthora (Etxeberria et al., 2011; Mayton et al., 2000). Some authors (Etxeberria et al., 2011; Pittis and Shattock, 1994; Sutherland and Cohen, 1983) also observed false positive results obtained with tetrazolium staining of oospores of different oomycete species. Therefore, in the temperature experiment described here, the viability of oospores was assessed using the plasmolysis method, providing lower estimates of oospore viability but no false positives (Etxeberria et al., 2011, Pittis and Shattock, 1994).

Laboratory experiments under controlled conditions at temperatures ranging from -24 to $10{ }^{\circ} \mathrm{C}$ showed that the difference in viability of oospores extracted from agar and leaf discs was nearly significant $(P=0.0509)$, regardless of the isolate or temperature tested. The viability ranged from 13.02 to $63.90 \%$ and from 7.77 to $63.37 \%$ for oospores produced in agar and leaf discs, respectively (Tab. I). There were no differences in oospore viability among the three different matings in the in vitro and in vivo substrates. Statistical analysis revealed that temperature significantly affected the viability of oospores produced in agar

I: Percentage of viable oospores formed from mating six different isolates of Phytophthora infestans after exposure to six different temperatures.

\begin{tabular}{|c|c|c|c|c|c|c|c|}
\hline \multirow{2}{*}{ Medium } & \multirow{2}{*}{ Mating A1:A2 } & \multicolumn{6}{|c|}{ Temperature/Viability (\%) } \\
\hline & & $10^{\circ} \mathrm{C}$ & $4^{\circ} \mathrm{C}$ & $0^{\circ} \mathrm{C}$ & $-4^{\circ} \mathrm{C}$ & $-10^{\circ} \mathrm{C}$ & $-24^{\circ} \mathrm{C}$ \\
\hline \multirow[t]{3}{*}{ Agar } & H6/09:M1/09 & $60.35 \pm 3.85$ & $60.40 \pm 3.87$ & $39.20 \pm 3.82$ & $34.67 \pm 8.01$ & $16.83 \pm 10.64$ & $18.99 \pm 6.70$ \\
\hline & JCl/09:V4/09 & $63.06 \pm 5.77$ & $47.40 \pm 5.06$ & $41.40 \pm 5.14$ & $42.23 \pm 3.82$ & $8.00 \pm 4.45$ & $18.99 \pm 9.41$ \\
\hline & L27/09:Bel/09 & $66.24 \pm 4.89$ & $65.89 \pm 6.21$ & $42.50 \pm 9.17$ & $43.83 \pm 2.67$ & $14.22 \pm 5.23$ & $13.41 \pm 5.36$ \\
\hline \multirow[t]{3}{*}{ Leaf disc } & H6/09:Ml/09 & $59.90 \pm 3.45$ & $59.80 \pm 3.94$ & $39.50 \pm 6.14$ & $24.90 \pm 9.43$ & $8.70 \pm 11.82$ & $11.10 \pm 7.78$ \\
\hline & JCl/09:V4/09 & $60.70 \pm 5.08$ & $64.90 \pm 5.17$ & $42.00 \pm 6.54$ & $32.40 \pm 4.22$ & $7.40 \pm 4.86$ & $11.10 \pm 10.45$ \\
\hline & L27/09:Bel/09 & $65.40 \pm 5.39$ & $65.40 \pm 6.34$ & $40.90 \pm 4.89$ & $33.70 \pm 3.26$ & $7.20 \pm 7.47$ & $4.90 \pm 5.96$ \\
\hline
\end{tabular}

Values are means \pm standard deviation

II: Percentage of viable oospores formed from mating six different isolates of Phytophthora infestans after exposure to field conditions in two localities from the end of October to the end of May.

\begin{tabular}{lccccc}
\hline \multirow{2}{*}{ Locality } & Mating A1:A2 & \multicolumn{4}{c}{ Year/Viability (\%) } \\
\cline { 3 - 6 } & & $\mathbf{2 0 1 1 - 2 0 1 2}$ & $\mathbf{2 0 1 2 - 2 0 1 3}$ & $\mathbf{2 0 1 3 - 2 0 1 4}$ & $\mathbf{2 0 1 4 - 2 0 1 5}$ \\
\hline Prague-Suchdol & H6/09:M1/09 & $30.80 \pm 2.04$ & $35.85 \pm 8.36$ & $35.17 \pm 8.37$ & $40.00 \pm 2.24$ \\
& JC1/09:V4/09 & $29.80 \pm 4.94$ & $40.53 \pm 2.78$ & $39.52 \pm 5.05$ & $40.70 \pm 6.10$ \\
\cline { 2 - 6 } Svitavy & L27/09:Be1/09 & $29.20 \pm 5.64$ & $34.96 \pm 8.03$ & $40.27 \pm 5.66$ & $42.80 \pm 9.06$ \\
& H6/09:M1/09 & $15.12 \pm 7.08$ & $15.87 \pm 7.01$ & $24.90 \pm 9.43$ & $37.69 \pm 4.25$ \\
& JC1/09:V4/09 & $17.91 \pm 5.63$ & $19.14 \pm 5.51$ & $32.40 \pm 4.22$ & $42.23 \pm 3.82$ \\
\hline & L27/09:Be1/09 & $13.41 \pm 5.36$ & $14.39 \pm 5.30$ & $33.70 \pm 3.26$ & $43.83 \pm 2.67$ \\
\hline
\end{tabular}

Values are means \pm standard deviation 
and leaf discs. There were significant differences $(\mathrm{P}=0.00002)$ in the viability of oospores in agar among temperatures, with the exception of 10 and $4{ }^{\circ} \mathrm{C}$, 0 and $-4{ }^{\circ} \mathrm{C}$, and -10 and $-24^{\circ} \mathrm{C}$. Significant differences among temperatures were also observed in leaf discs ( $\mathrm{P}=0.00002$ or 0.000057$)$. There was no difference between the temperatures of 10 and $4{ }^{\circ} \mathrm{C}$ and between those of -10 and $-24^{\circ} \mathrm{C}$. The optimum temperature range for maximum oospore survival was $4-10^{\circ} \mathrm{C}$ in agar and in leaf discs (Tab. I). Our findings are somewhat contrary to those reported by Medina and Platt (1999). These authors demonstrated greater viabilities of oospores exposed to temperatures of -50 and $-20{ }^{\circ} \mathrm{C}$ than of those exposed to 0 , 4 , or $15^{\circ} \mathrm{C}$. Drenth et al. (1995) found that oospores can survive $48 \mathrm{~h}$ of exposure to $-80^{\circ} \mathrm{C}$, but not after treatments of $40^{\circ} \mathrm{C}$ and higher. The results of both studies indicate that low, subfreezing temperatures support oospore survival and even conserve their viability better than do warmer temperatures. In Europe, this pattern was observed in Nordic countries, where oospore-derived infections changed the epidemiology of potato late blight (Yuen and Andersson, 2013).

Oospores of P. infestans originating from matings of six isolates in three different combinations were viable after a seven-month exposure to natural conditions in two localities. In the Prague-Suchdol locality, oospore viability ranged from 29 to $43 \%$ based on the plasmolysis test during four winter periods. On average, the percent of plasmolyzed oospores was found to be between 15 and $44 \%$ in the Svitavy locality. For both localities, the lowest oospore viability was recorded for the period of 2011-2012, while during the period of 2014-2015, oospores had the highest average percent viability (Tab. II). Oospore viability was higher in Prague-Suchdol than in Svitavy for the 2011-12, 2012-13 and 2013-14 overwintering studies $(\mathrm{P}=0.00011, \mathrm{P}=0.00011$ and $\mathrm{P}=0.000218$, respectively), while during the 2014-15 period, no significant difference $(\mathrm{P}=0.934)$ in oospore viability was found between localities (Tab. II). The viability of oospores differed significantly for the overwintering periods in each locality. In Svitavy, there were significant differences between study periods ( $\mathrm{P}=0.000137)$, with the exceptions of $2011-12$ and 2012-13. Significant differences were also found in Prague-Suchdol, but only between 2011-12 and the following overwintering periods ( $\mathrm{P}=0.000409$, 0.000150 and 0.000137 , respectively). Medina and Platt (1999) state that oospores can overwinter in soil under Canadian environmental conditions. They also demonstrated that oospores originating from different mating type combinations varied in their viability, germination and infectivity when exposed to different environmental conditions. We also observed variability in oospore viability among different matings, but with no significant differences. As seen in Tab. II, the viability of oospores originating from different matings also varied among all years of the survey.

Although oospore presence in the sampled fields was not confirmed in this study, the occurrence of both mating types (Sedlák et al., 2017) may initiate sexual reproduction in the Czech P. infestans population, and the results of this study indicate the possibility of surviving oospores in the Czech Republic. To verify that sexual or only clonal reproduction has occurred in the Czech Republic, genotyping using SSR markers would be required to reveal genetic variability in the Czech P.infestans population (Li et al., 2013).

\section{CONCLUSION}

The results presented here confirmed that there is a possibility of survival of P. infestans oospores under the environmental conditions of the Czech Republic. However, other factors influencing oospore survival in soil (e.g., the effect of microorganisms in soil, soil moisture and temperature, soil texture, and crop rotation) must be taken into consideration when examining the role of P. infestans oospores as another source of primary inoculum of the pathogen. Therefore, it is important to continue studying oospore survival under "real" natural soil conditions and in response to factors affecting the production, germination and infectivity of oospores under the field conditions of the Czech Republic.

Acknowledgements

Supported by the Ministry of Agriculture of the Czech Republic, Project No. QJ1210305.

\section{REFERENCES}

ANDERSSON, B., SANDSTRÖM, M. and STRÖMBERG, A. 1998. Indications of soil borne inoculum of Phytophthora infestans. Potato Research, 41(4): 305-310.

COHEN, Y., FARKASH, S., BAIDER, A. and SHAW, D. S. 2000. Sprinkling irrigation enhances production of oospores of Phytophthora infestans in field-grown crops of potato. Phytopathology, 90(10): 1105-1111.

COHEN, Y., FARKASH, S., RESHIT,Z. and BAIDER, A. 1997. Oospore production of Phytophthora infestans in potato and tomato leaves. Phytopathology, 87(2): 191-196.

DRENTH, A., JANSSEN, E. M. and GOVERS, F. 1995. Formation and survival of oospores of Phytophthora infestans under natural conditions. Plant Pathology, 44(1): 86-94. 
DRENTH, A., TAS, I. C. Q. and GOVERS, F. 1994. DNA fingerprinting uncovers a new sexually reproducing population of Phytophthora infestans in the Netherlands. European Journal of Plant Pathology, 100(2): 97-107.

ETXEBERRIA, A., MENDARTE, S. and LARREGLA, S. 2011. Determination of viability of Phytophthora capsici oospores with the tetrazolium bromide staining test versus a plasmolysis method. Revista Iberoamericana de Micologia, 28(1): 43-49.

FLIER, W. G., GRÜNWALD, N. J., FRY, W. E. and TURKENSTEEN, L. J. 2001. Formation, production and viability of oospores of Phytophthora infestans from potato and Solanum demissum in the Toluca Valley, central Mexico. Mycological Research, 105(8): 998-1006.

FRY, W. 2008. Phytophthora infestans: the plant (and R gene) destroyer. Molecular Plant Pathology, 9(3), 385-402.

FRY, W. E., BIRCH, P. R. J., JUDELSON, H. S., GRÜNWALD, N. J., DANIES, G., EVERTS, K. L., GEVENS, A.

J., GUGINO, B. K., JOHNSON, D. A., JOHNSON, S. B., MCGRATH, M. T., MYERS, K. L., RISTAINO, J.

B., ROBERTS, P. D., SECOR, G. and SMART, C. D. 2015. Five reasons to consider Phytophthora infestans a reemerging pathogen. Phytopathology, 105(7): 966-981.

FRY, W. E. and GOODWIN, S. B. 1997a. Re-emergence of potato and tomato late blight in the United States. Plant Disease, 81(12): 1349-1357.

FRY, W. E. and GOODWIN, S. B. 1997b. Resurgence of the Irish potato famine fungus. BioScience, 47(6): 363-371.

FRY, W. E., MCGRATH, M. T., SEAMAN, A., ZITTER, T. A., MCLEOD, A., DANIES, G., SMALL, I. M., MYERS, K., EVERTS, K., GEVENS, A. J., GUGINO, B. K., JOHNSON, S. B., JUDELSON, H., RISTAINO, J., ROBERTS, P., SECOR, G., SEEBOLD, K., SNOVER-CLIFT, K., WYENANDT, A., GRÜNWALD, N. J. and SMART, C. D. 2013. The 2009 late blight pandemic in the eastern United States - causes and results. Plant Disease, 97(3): 296-306.

GAVINO, P. D., SMART, C. D., SANDROCK, R. W., MILLER, J. S., HAMM, P. B., T., Y. L., DAVIS, R. M. and FRY, W. E. 2000. Implications of sexual reproduction for Phytophthora infestans in the United States: generation of an aggressive lineage. Plant Disease, 84(7): 731-735.

GOODWIN, S. B. 1997. The population genetics of Phytophthora. Phytopathology, 87(4): 462-473.

GOODWIN, S. B., COHEN, B. A. and FRY, W. E. 1994. Panglobal distribution of a single clonal lineage of the Irish potato famine fungus. Proceedings of the National Academy of Sciences of the United States of America, 91(24): 11591-11595.

GÖTZ, E. 1991. Untersuchungen zum Auftreten des A2-Paarungstyps bei Phytophthora infestans (Mont.) de Bary in Ostdeutschland. Potato Research, 34(3): 233-237.

HOHL, H. R. and ISELIN, K. 1984. Strains of Phytophthora infestans from Switzerland with A2 mating type behaviour. Transactions of the British Mycological Society, 83(3): 529-530.

JUDELSON, H. S. 2007. Sexual reproduction in plant pathogenic oomycetes: biology and impact on disease. In: HEITMAN, J., KRONSTAD, J., TAYLOR, J. and CASSELTON, L. (Eds.). Sex in Fungi. Washington, DC., USA: ASM Press.

KAMOUN, S., FURZER, O., JONES, J. D. G., JUDELSON, H. S., ALI, G. S., DALIO, R. J. D., ROY, S. G., SCHENA, L., ZAMBOUNIS, A., PANABIĖRES, F., CAHILL, D., RUOCCO, M., FIGUEIREDO, A., CHEN, X.-R., HULVEY, J., STAM, R., LAMOUR, K., GIJZEN, M., TYLER, B. M., GRÜNWALD, N. J., MUKHTAR, M. S., TOMÉ, D. F. A., TÖR, M., VAN DEN ACKERVEKEN, G., MCDOWELL, J., DAAYF, F., FRY, W. E., LINDQVIST-KREUZE, H., MEIJER, H. J. G., PETRE, B., RISTAINO, J., YOSHIDA, K., BIRCH, P. R. J. and GOVERS, F. 2015. The Top 10 oomycete pathogens in molecular plant pathology. Molecular Plant Pathology, 16(4): 413-434.

KNAPOVA, G. and GISI, U. 2002. Phenotypic and genotypic structure of Phytophthora infestans populations on potato and tomato in France and Switzerland. Plant Pathology, 51(5): 641-653.

LI, Y., COOKE, D. E. L., JACOBSEN, E. and VAN DER LEE, T. 2013. Efficient multiplex simple sequence repeat genotyping of the oomycete plant pathogen Phytophthora infestans. Journal of Microbiological Methods, 92(3):316-322.

MAYTON, H., SMART, C. D., MORAVEC, B. C., MIZUBUTI, E. S. G., MULDOON, A. E. and FRY, W. E. 2000. Oospore survival and pathogenicity of single oospore recombinant progeny from a cross involving US-17 and US-8 genotypes of Phytophthora infestans. Plant Disease, 84(11): 1190-1196.

MAZÁKOVÁ, J., TÁBORSKÝ, V., ZOUHAR, M., RYŠÁNEK, P., HAUSVATER, E. and DOLEŽAL, P. 2006. Occurrence and distribution of mating types Al and A2 of Phytophthora infestans (Mont.) de Bary in the Czech Republic. Plant Protection Science, 42(2): 41-48.

MAZÁKOVÁ, J., ZOUHAR, M., RYŠÁNEK, P., TÁBORSKY, V., HAUSVATER, E. and DOLEŽAL, P. 2010. Mating type distribution of Phytophthora infestans (Mont.) de Bary in the Czech Republic in 2007 and 2008. Plant Protection Science, 46(3): 89-97.

MEDINA, M. V. and PLATT, H. W. 1999. Viability of oospores of Phytophthora infestans under field conditions in northeastern North America. Canadian Journal of Plant Pathology, 21(2): 137-143.

NIEDERHAUSER, J.S. 1991. Phytophthora infestans: the Mexican connection. In:LUCAS, J.A., SHATTOCK, R. C., SHAW, D. S. and COOKE, L. R. (Eds.). Phytophthora. Cambridge, GB: British Mycological Society, Cambridge University Press. 
OLIVA, R. F., ERSELIUS, L. J., ADLER, N. E. and FORBES, G. A. 2002. Potential of sexual reproduction among host-adapted populations of Phytophthora infestans sensu lato in Ecuador. Plant Pathology, 51(6): 710-719. PIPE, N. D., AZCOITIA, V. and SHAW, D. S. 2000. Self-fertility in Phytophthora infestans: heterokaryons segregate several phenotypes. Mycological Research, 104(6): 676-680.

PITTIS, J. E. and SHATTOCK, R. C. 1994. Viability, germination and infection potential of oospores of Phytophthora infestans. Plant Pathology, 43(2): 387-396.

SEDLÁK, P., MAZÁKOVÁ, J., SEDLÁKOVÁ, V., RYŠÁNEK, P., VEJL, P. and DOLEŽAL, P. 2017. Virulence and mating type of Phytophthora infestans isolates in the Czech Republic. Scientia Agriculturae Bohemica, 48(4): 185-192.

SUJKOWSKI, L. S., GOODWIN, S. B., DYER, A. T. and FRY, W. E. 1994. Increased genotypic diversity via migration and possible occurrence of sexual reproduction of Phytophthora infestans in Poland. Phytopathology, 84(2): 201-207.

SUTHERLAND, E. D. and COHEN, S. D. 1983. Evaluation of tetrazolium bromide as a vital stain for fungal oospores. Phytopathology, 73(11): 1532-1535.

TURKENSTEEN, L. J., FLIER, W. G., WANNINGEN, R. and MULDER, A. 2000. Production, survival and infectivity of oospores of Phytophthora infestans. Plant Pathology, 49(6): 688-696.

YOSHIDA, K., SCHUENEMANN, V. J., CANO, L. M., PAIS, M., MISHRA, B., SHARMA, R., LANZ, C., MARTIN, F. N., KAMOUN, S., KRAUSE, J., THINES, M., WEIGEL, D. and BURBANO, H. A. 2013. The rise and fall of the Phytophthora infestans lineage that triggered the Irish potato famine. eLife, 2: e00731.

YUEN, J. E. and ANDERSSON, B. 2013. What is the evidence for sexual reproduction of Phytophthora infestans in Europe? Plant Pathology, 62(3): 485-491. 